\title{
CT findings of the temporal bone in CHARGE syndrome: aspects of importance in cochlear implant surgery
}

\author{
A. C. Vesseur ${ }^{1}$ B. M. Verbist ${ }^{2,3}$ - H. E. Westerlaan ${ }^{4}$ F. J. J. Kloostra ${ }^{5}$. \\ R. J. C. Admiraal ${ }^{1}$. C. M. A. van Ravenswaaij-Arts ${ }^{6} \cdot$ R. H. Free ${ }^{5}$. \\ E. A. M. Mylanus ${ }^{1}$
}

Received: 13 December 2015/Accepted: 11 June 2016/Published online: 20 June 2016

(c) The Author(s) 2016. This article is published with open access at Springerlink.com

\begin{abstract}
To provide an overview of anomalies of the temporal bone in CHARGE syndrome relevant to cochlear implantation (CI), anatomical structures of the temporal bone and the respective genotypes were analysed. In this retrospective study, 42 CTs of the temporal bone of 42 patients with CHARGE syndrome were reviewed in consensus by two head-and-neck radiologists and two otological surgeons. Anatomical structures of the temporal bone were evaluated and correlated with genetic data. Abnormalities that might affect CI surgery were seen, such as a vascular structure, a petrosquamosal sinus (13\%), an underdeveloped mastoid $(8 \%)$ and an aberrant course of the facial nerve crossing the round window $(9 \%)$ and/or the promontory $(18 \%)$. The appearance of the inner ear varied widely: in $77 \%$ of patients all semicircular canals were absent and the cochlea varied from normal to hypoplastic. A stenotic cochlear aperture was observed in
\end{abstract}

A. C. Vesseur

Annemarie.vesseur@radboudumc.nl

1 Department of ENT, Radboud University Medical Centre, Postbus 9101, 6500 HB Nijmegen, The Netherlands

2 Department of Radiology, Radboud University Medical Centre, Postbus 9101, 6500 HB Nijmegen, The Netherlands

3 Department of Radiology, Leiden University Medical Centre, Postbus 9600, 2300 RC Leiden, The Netherlands

4 Department of Radiology, University Medical Centre Groningen, University of Groningen, Postbus 30.001, 9700 RB Groningen, The Netherlands

5 Department of ENT, University Medical Centre Groningen, University of Groningen, Postbus 30.001, 9700 RB Groningen, The Netherlands

6 Department of Genetics, University Medical Centre Groningen, University of Groningen, Postbus 30.001, 9700 RB Groningen, The Netherlands
$37 \%$. The middle ear was often affected with a stenotic round $(14 \%)$ or oval window $(71 \%)$. More anomalies were observed in patients with truncating mutations than with non-truncating mutations. Temporal bone findings in CHARGE syndrome vary widely. Vascular variants, aberrant route of the facial nerve, an underdeveloped mastoid, aplasia of the semicircular canals, and stenotic round window may complicate cochlear implantation.

Keywords CHARGE syndrome - Cochlear implant . Anatomy · Genetics · Temporal bone

\section{Introduction}

The criteria for the clinical diagnosis of CHARGE syndrome (MIM, Mendelian Inheritance in Man, 214800), have been defined by Blake et al. and Verloes [1, 2]. CHARGE syndrome is an acronym of Coloboma, Heart disease, choanal Atresia, Retardation, Genital hypoplasia, and Ear anomalies. Organ involvement and severity is highly variable amongst affected patients. A major criterion includes the condition of the temporal bone, which may be hypoplastic or show an absence of the semicircular canals, according to Verloes. Anomalies are seen in the external, middle and inner ear, such as the typically lowset, cup-shaped ears, ossicular malformations, an aberrant course of the facial nerve, hypoplastic internal auditory canal, and an abnormally developed cochlea. Some of these malformations can cause hearing loss: $60-90 \%$ of patients with CHARGE syndrome have moderate to severe hearing loss due to conductive, sensorineural or mixed defects. In most patients, hearing loss can be partially compensated with hearing aids. When hearing aids do not have the desired outcome due to the presence of profound to severe 
hearing loss, cochlear implantation may be considered. If cognitive disabilities, developmental and behavioural problems do not preclude cochlear implantation, a thorough assessment of the temporal bone anatomy is necessary. Anatomical alterations pose additional surgical risks during the implantation, by hampering the surgical approach to the cochlea or the insertion of the electrode array into the cochlea, and they may influence the surgical results in terms of speech perception.

In 2004, the causative gene for CHARGE syndrome was identified as $C H D 7$ on chromosome 8q12.1 [3]. Since then, 528 different mutations of the gene have been described, but no clear genotype-phenotype correlation could be recognized (www.CHD7.org) [4]. In the CHD7 mutation positive patients, the most common clinical findings were temporal bone anomalies $(98 \%)$, external ear malformations (91\%), and hearing loss (89\%) [5].

The main goal of this retrospective study was to analyse the presence of the anomalies of the temporal bone and the cochlear nerve in patients with CHARGE syndrome and their potential impact on cochlear implant surgery planning. The secondary goal was to study possible genotypephenotype correlations.

\section{Materials and methods}

We collected analogue and digital CT studies of the temporal bone of patients attending the Dutch CHARGE center of expertise (University Medical Center Groningen, the Netherlands), after obtaining written informed consent from all patients or their legal representatives.

All patients had molecularly confirmed CHARGE syndrome, or clinically typical CHARGE syndrome according to the Blake or Verloes criteria (Tables 1,4) except for one patient with atypical CHARGE syndrome (patient 12), because the parents did not wish further investigation $[1,2]$.

The patients were investigated in different time periods and in different Dutch hospitals, so the scans were made with different scanner types and variable scan parameters.

We evaluated CTs of 84 ears of 42 patients (22 male, 20 female) with CHARGE syndrome (29 digital and 13 analogue scans). The scans were performed between 19962010. The mean age of the patients at the time of scanning was 6.4 years, median 2.5 years (SD 9.8; $\min 0$, max 47 years).

\section{Imaging analysis}

All imaging studies were evaluated by four observers (two head-and-neck radiologists with 13 and 7 years of experience and two otorhinolaryngologists with 10 and 15 years of experience), who then met to reach a consensus opinion. The reviewers had no access to patients' names or their clinical information. Each ear was evaluated separately, in axial and coronal planes, if available. The anatomic structures and normative measures determined are presented in Table 9 in "Appendix" and Fig. 1.

All the scans were analysed as extensively as possible, using a standardized form (Table 10 in "Appendix") compiled specifically for this study. Items that could not be analysed, e.g. due to a missing coronal plane or to slice thickness, were scored as 'unable to identify' (UTI).

The digital scans were analysed on a viewing station (IMPAX, Apache Software Foundation, Version 2.0, January 2004). Measurements were obtained in millimetre (to two decimal places) with electronic calipers provided by the pacs-system. Analogue films were evaluated on an illuminated view box and measurements were performed with an analogue ruler. If a structure could not be properly assessed, it was scored as 'unable to identify' (UTI).

SPSS 20 was used to collect all data and perform statistical analyses. We used the $\chi^{2}$ test to test for significant correlations.

\section{CHD7 analysis}

The results of $C H D 7$ analysis were already known for all but one (patient 12) patient. The analyses were performed

Table 1 Characteristics of CHARGE syndrome

\begin{tabular}{l} 
a. Major and minor signs of CHARGE syndrome [2] \\
Major signs \\
Coloboma (iris or choroid, with or without microphthalmia) \\
Atresia of choanae \\
Hypoplastic semicircular canals \\
Minor signs \\
Rhombencephalic dysfunction (brainstem dysfunctions, cranial \\
nerve VII to XII palsies and neurosensory deafness) \\
Hypothalamo-hypophyseal dysfunction (including GH and \\
gonadotrophin deficiencies) \\
Abnormal middle or external ear \\
Malformation of mediastinal organs (heart, oesophagus) \\
Intellectual disability \\
b. Definition of typical, atypical, and partial CHARGE syndrome \\
[2] \\
Typical CHARGE syndrome \\
3 major signs \\
$2 / 3$ major signs $+2 / 5$ minor signs \\
Partial/incomplete CHARGE \\
$2 / 3$ major signs $+1 / 5$ minor signs \\
Atypical CHARGE \\
$2 / 3$ major signs $+0 / 5$ minor signs \\
$1 / 3$ major signs $+3 / 5$ minors signs \\
\hline
\end{tabular}



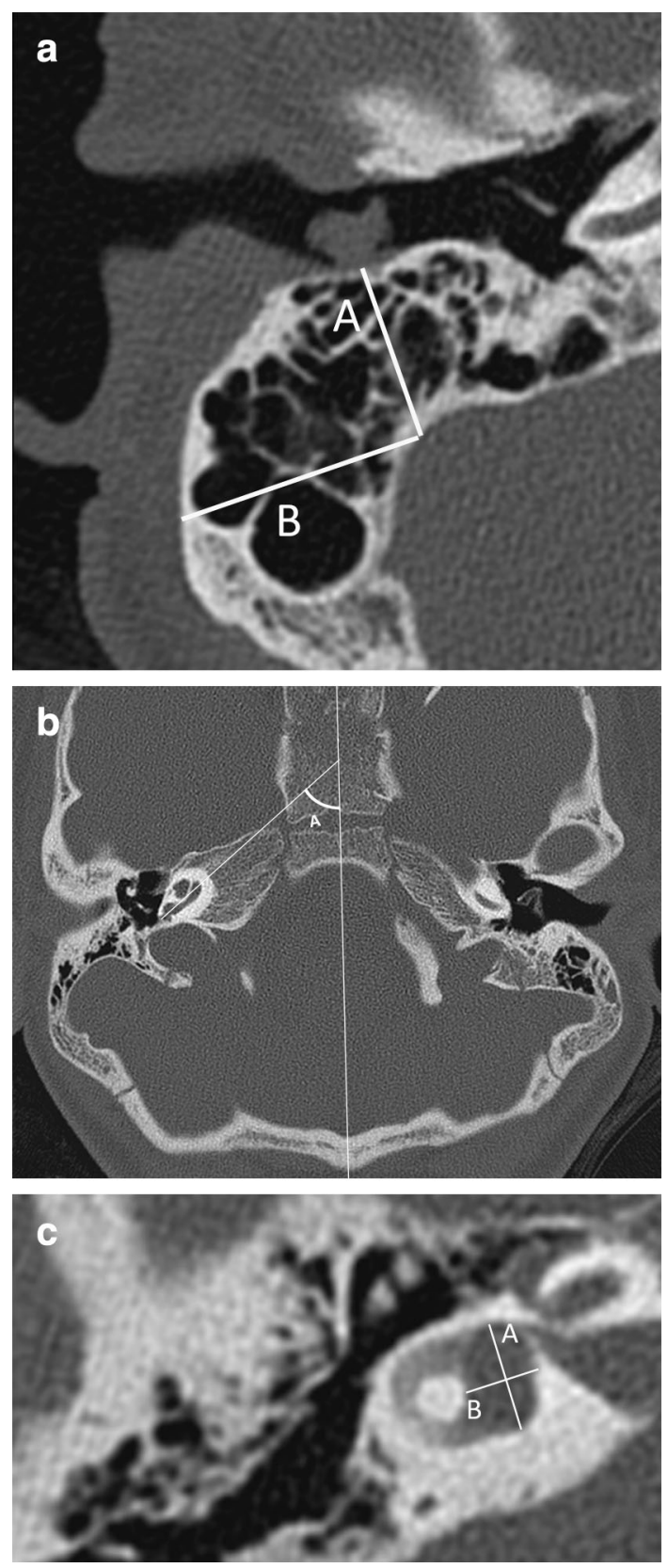

Fig. 1 Measurements in axial CT images. a Mastoid size $A$ anteriorposterior (AP) size, measured in the middle of the external meatus (cranial/caudal) as the minimal distance from the external meatus to sigmoid sinus $B$ lateral-medial (LM) size, distance between outer cortex and sigmoid sinus, measured perpendicular to A. b Angle cochlear basal turn. c Vestibulum size $A$ longitudinal extension, $B$ transversal diameter (right ear)

on DNA isolated from peripheral blood cells according to standard procedures. The 37 coding exons of $\mathrm{CHD} 7$ (exons 2-38, RefSeq NM_017780.02) and their flanking intron sequences were amplified by PCR and sequenced as described earlier [3]. If no mutations were identified, CHD7 was screened for whole exon deletions and
Table 2 Ear structure observations

\begin{tabular}{|c|c|c|c|}
\hline Structure on $\mathrm{CT}$ & Normal & Abnormal & UTI \\
\hline \multirow[t]{2}{*}{ Pneumatisation mastoid } & Good & No cells & UTI \\
\hline & $73(87 \%)$ & $7(8 \%)$ & $4(5 \%)$ \\
\hline \multirow[t]{2}{*}{ Middle ear cavity size } & Normal & Small/large & UTI \\
\hline & $84(100 \%)$ & 0 & 0 \\
\hline \multirow[t]{2}{*}{ Jugular bulb } & Normal & High & UTI \\
\hline & $59(70 \%)$ & $23(27 \%)$ & $2(2 \%)$ \\
\hline \multirow[t]{2}{*}{ Emissary veins } & Total & $>1 \mathrm{~mm}$ & PSS \\
\hline & $28(33 \%)$ & $25(30 \%)$ & $11(13 \%)$ \\
\hline Windows & Present & Absent/stenotic & UTI \\
\hline Oval & $22(26 \%)$ & $60(71 \%)$ & $2(2 \%)$ \\
\hline Round & $70(83 \%)$ & $12(14 \%)$ & $2(2 \%)$ \\
\hline Ossicles & Normal & Dysplastic & UTI \\
\hline Malleus & $83(99 \%)$ & $1(1 \%)$ & 0 \\
\hline Incus & $75(89 \%)$ & $9(11 \%)$ & 0 \\
\hline Stapes & $27(32 \%)$ & $42(50 \%)$ & $13(15 \%)$ \\
\hline Facial nerve & Normal & Aberrant course & UTI \\
\hline Tympanic & $54(64 \%)$ & $24(29 \%)$ & $6(7 \%)$ \\
\hline Mastoid & $70(83 \%)$ & $6(7 \%)$ & $8(10 \%)$ \\
\hline \multirow[t]{2}{*}{ Vestibular aqueduct } & Normal & Aberrant course & UTI \\
\hline & $12(14 \%)$ & $57(68 \%)$ & $12(14 \%)$ \\
\hline \multirow[t]{2}{*}{ Cochlear apertura } & Normal & Stenotic & UTI \\
\hline & $51(61 \%)$ & $31(37 \%)$ & $2(2,4 \%)$ \\
\hline \multirow[t]{2}{*}{ SCC } & Normal & Aplastic & Dysplastic \\
\hline & $2(2 \%)$ & $65(77 \%)$ & $17(20 \%)$ \\
\hline
\end{tabular}

Number of ears: 84

UTI unable to identify; PPS persistent petrosquamosal sinus, SCC semicircular canals

duplications by multiplex ligation-dependent probe amplification (MLPA) using a commercially available set of probes: the SALSA P201 kit (MRC-Holland, Amsterdam, the Netherlands; http://www.mrc-holland.com) [6].

Nonsense and frameshift mutations and whole-gene or whole-exome deletions were categorised as truncating mutations, while missense and splice site mutations were categorised as non-truncating.

\section{Results}

\section{Mastoid and vascular structures (Tables 2, 3)}

The first part of a cochlear implantation, the mastoidectomy, can be challenging in an underdeveloped mastoid. The AP-size (anterior-posterior) and the LM-size (lateralmedial) of the mastoid could not be measured in 21 ears (25\%), because of a hardly developed mastoid or moderate quality of the scan. These patients were particularly young (median age 5 years, mean 8.5 years, $22 \%<1$-year-old). 
Table 3 Ear structure measurements

\begin{tabular}{lccllll}
\hline Structure & Mean $(\mathrm{mm})$ & Median $(\mathrm{mm})$ & SD $(\mathrm{mm})$ & Max $(\mathrm{mm})$ & Min $(\mathrm{mm})$ & UTI (ears) \\
\hline Mastoid & & & & & & \\
AP-size & 10.6 & 11.0 & 3.2 & 19.4 & 5.0 & 21 \\
LM-size & 7.9 & 7.0 & 6.2 & 40.0 & 1.2 & 22 \\
Vestibulum & & & & & \\
Length & 4.7 & 4.7 & 1.0 & 9.0 & 2.9 & 0 \\
Width & 2.3 & 2.3 & 0.6 & 5.0 & 1.0 & 1.0 \\
VA diameter & & & & & & 11 \\
IAC & 0.7 & 0.6 & 0.3 & 1.9 & 0.1 & 0 \\
\hline
\end{tabular}

Number of ears: 84

${ }^{\text {a }}$ only digital scans $(n=58)$

$A P$ anterior-posterior, $L M$ lateral-medial, $V A$ vestibular aqueduct, $I A C$ internal auditory canal, $S D$ standard deviation, UTI unable to identify

In 25 ears $(29.8 \%)$, an emissary vein with a diameter larger than $1 \mathrm{~mm}$ was present (Fig. 2a, b).

\section{Middle ear (windows/ossicles/facial nerve) (Tables 2, 3)}

Middle ear anomalies can be a challenge in preparing and making the cochleostomy. The size of the middle ear cavity was within normal limits in all patients and thus will not pose a problem in surgery. Overall, there was an aberrant course of the tympanic part of the facial nerve crossing the promontory in 16 ears (19.0\% of the total number of ears) and in eight ears also the round window $(9.5 \%$ of the total number of ears). The aberrant mastoidal portion of the facial nerve seemed to run more medially than normal in four ears. The windows and ossicles were difficult to assess due either to otitis media or to the moderate quality of the scan in 20 patients $(23.8 \%)$.

In 43 ears $(51.2 \%)$ with a stenotic oval window, the stapes was not identifiable or dysplastic, either presenting as a monopod stapes (one ear), or displaced on the promontory or into the middle ear cavity (six ears) (Fig. 3).

\section{Cochleovestibular system (Tables 5, 6)}

Abnormalities of the cochlea can complicate the insertion of the electrode array. Table 5 shows the distribution of cochlear type, omitting patient 12 (who had no mutation found and normal cochleas), and patient 30 (who had a UV missense mutation, one normal cochlea and one cochlear hypoplasia type IV). In 32 (38.1\%) ears, an abnormal cochlea was seen. The ears with an incomplete partition type II (IPII) deformity of the cochlea did not show an enlarged vestibular aqueduct or dilated vestibulum. In 22 (26.2 \%) ears, the cochlea appeared abnormal, but the type of dysplasia could not be determined according to
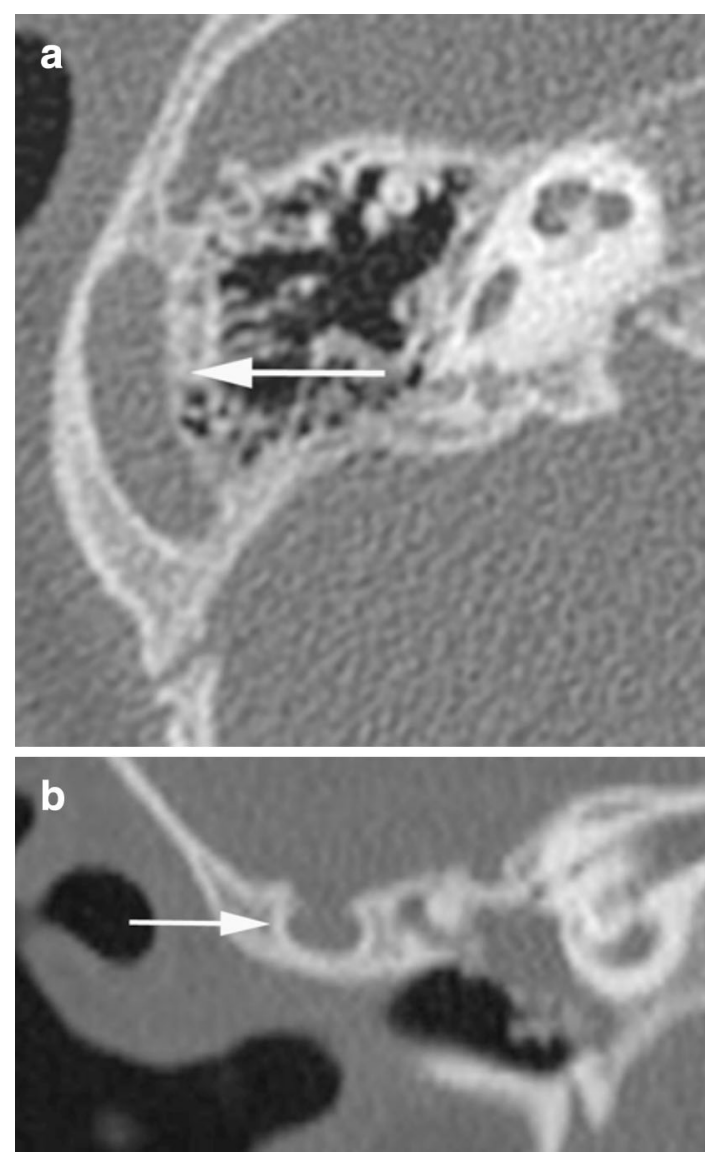

Fig. 2 Petrosquamosal sinus. Axial (a) and coronal (b) CT image of a right ear showing this emissary vein coursing along the lateral superior surface of the temporal bone. The petrosquamosal sinus originates at the transverse sinus and drains either into the retromandibular vein or the pterygoid venous plexus

Sennaroglu's classification (Fig. 4a-c). In these cochleae, the second turn seemed not to have developed fully, but the apex and basal turn were normal, with normal presence of 

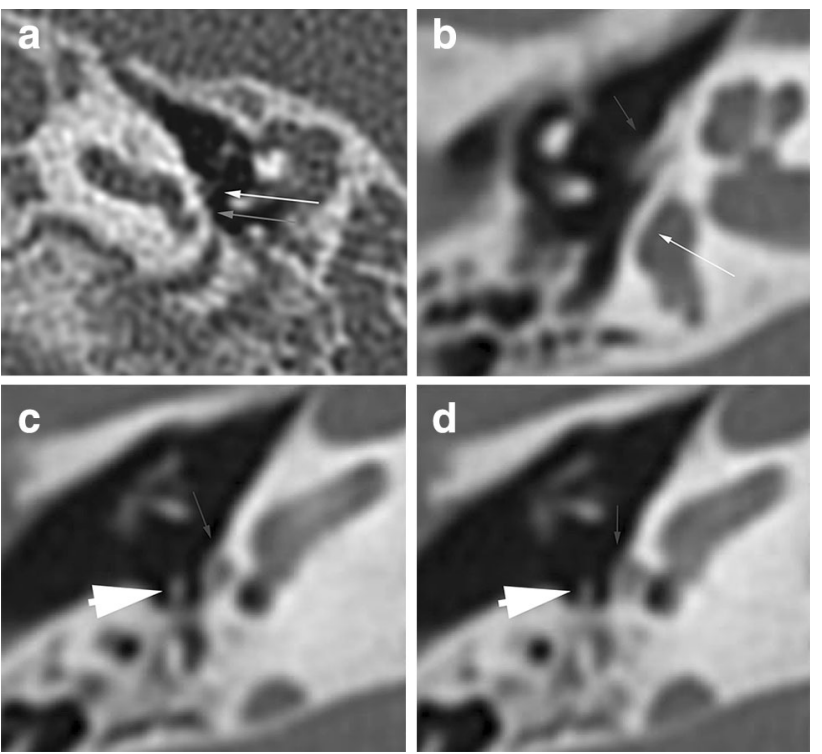

Fig. 3 Examples of window stenosis. a Axial CT image showing stenosis of the round window niche (grey arrow) in a left ear. Note also dysplastic stapes on the promontory (white arrow). b-d Axial CT images showing atresia of the oval window (thin arrow), aberrant course of the facial nerve crossing the round window (arrowhead) and a dysplastic stapes positioned at the sinus tympani (thick arrow). Note aplasia of the semicircular canals

interscalar septae and spiral osseous lamina, and in all but two of them the modiolus was normal. We will refer to this as hypoplasia type IV.

The angle of the basal turn was only measured on the digital scans; the mean was $57^{\circ}$ (SD 6.3), with a range from $43.5^{\circ}$ to $78.6^{\circ}$. The mean age of this group was 3.7 years.

Table 6 shows the distribution of SCC malformations excluding patient 12 (no mutation found and dysplasia of LSCC bilaterally) and patient 30 (UV missense mutation and total aplasia of SCC bilaterally). Aplasia of all SCCs was seen in 65 ears $(77.3 \%)$, while dysplasia of one or all SCCs was seen in 17 ears (20.2\%) and ranged from the strongly reduced development of one canal, like a bud, to just one affected canal (while the other two were present and normal) (Fig. 5a, b). In ears with a solitary canal aplasia or dysplasia, it was the lateral semicircular canal that was most often affected. If the superior semicircular canal was dysplastic, the lateral and posterior semicircular canals were absent.

Generally, the vestibulum was smaller than normal, both in length and width. The aberrant vestibular aqueducts had a course mainly in a perpendicular line from the vestibulum to the posterior fossa. If SCCs were absent, the aqueduct showed a more medial course than when they were severe or mild dysplastic. We found one ear with a large vestibular aqueduct (1.9 $\mathrm{mm}$ diameter), but normally developed cochlea.

\section{Cochlear aperture and inner ear (Table 2)}

In 13 of 31 ears with a stenotic aperture, the cochlea was abnormal (one incomplete partitioning type II, three hypoplasia type III, and nine type IV) (Table 2; Fig. 6).

\section{Surgical challenges}

Table 7 summarizes the observed anomalies expecting to be challenging in cochlear implant surgery. Figure 7 illustrates the differences in mastoid size between an ear with a small mastoid and an ear with a wide mastoid (APsize).

\section{Phenotypes}

No typical CHARGE phenotype of the temporal bone, i.e. a constant combination of several anomalies, could be determined. Some combinations of anomalies which were often seen are presented in Table 8. More than two-thirds of the patients $(68 \%)$ had an aberrant course of the vestibular aqueduct, and more than two-thirds (77 \%) had aplasia of the SCC.

\section{Genotypes (Table 4)}

The results of $C H D 7$ analysis were available for all 42 patients. We had 25 patients (50 ears, $59.5 \%$ of 84 ears) with a truncating mutation (of which were $56 \%$ nonsense, $20 \%$ frameshift, $4 \%$ deletions) and 15 patients (30 ears, $35.7 \%$ of 84 ears) with a non-truncating mutation (47\% missense, $53 \%$ splice site). In one patient an unclassified CHD7 variant was detected (UV-missense) and in another patient no CHD7 mutation was found. Remarkably, 12/42 patients did not fully comply with the clinical diagnostic criteria [2]. Of these 12 patients, eight had a non-truncating mutation, in one patient no mutation was found, and in another only an unclassified variant could be detected in CHD7. Thus, only 2/12 atypical patients (16.7\%) had a truncating mutation. In contrast, truncating mutations were found in $23 / 30$ patients $(76.7 \%$ ) who had clinically typical CHARGE syndrome.

Because no constant combination of anomalies could be identified, no correlation could be made between phenotype and genotype. Nevertheless, of the surgical challenging anomalies, SCC aplasia (Table 6) and oval window atresia (truncating $72 \%, P=0.001$ ) were found more frequently in patients with truncating mutations than in those with non-truncating mutations $(P<0.05)$ (Chisquared test). Cochlear anomalies (Table 5), petrosquamosal sinus (73\% truncating, $P=0.679)$ and an aberrant course of the tympanic portion of the facial nerve (67\% truncating, $P=0.602$ ) were also found more 
a

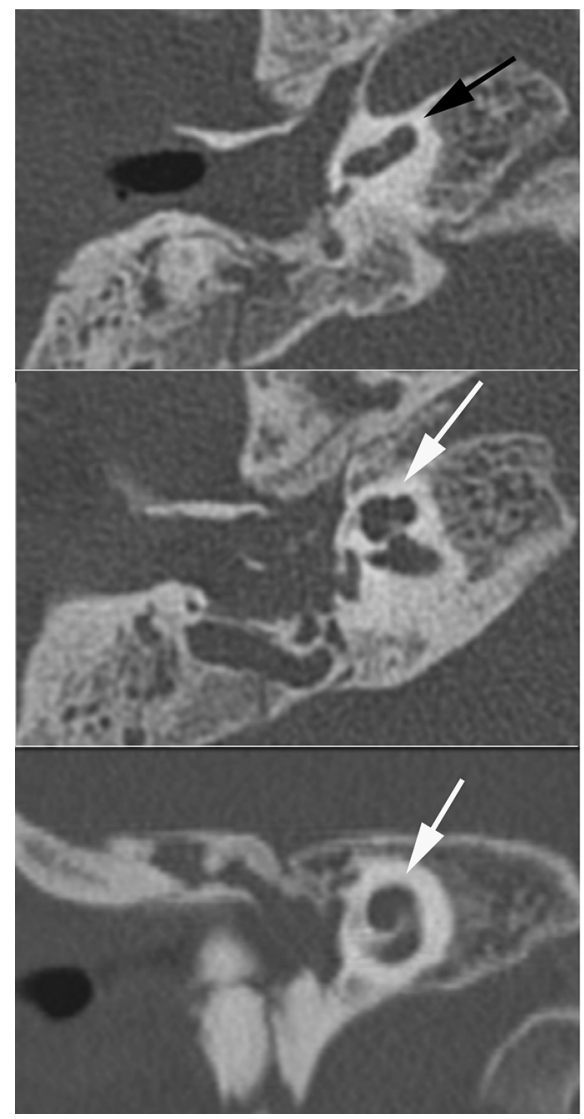

b

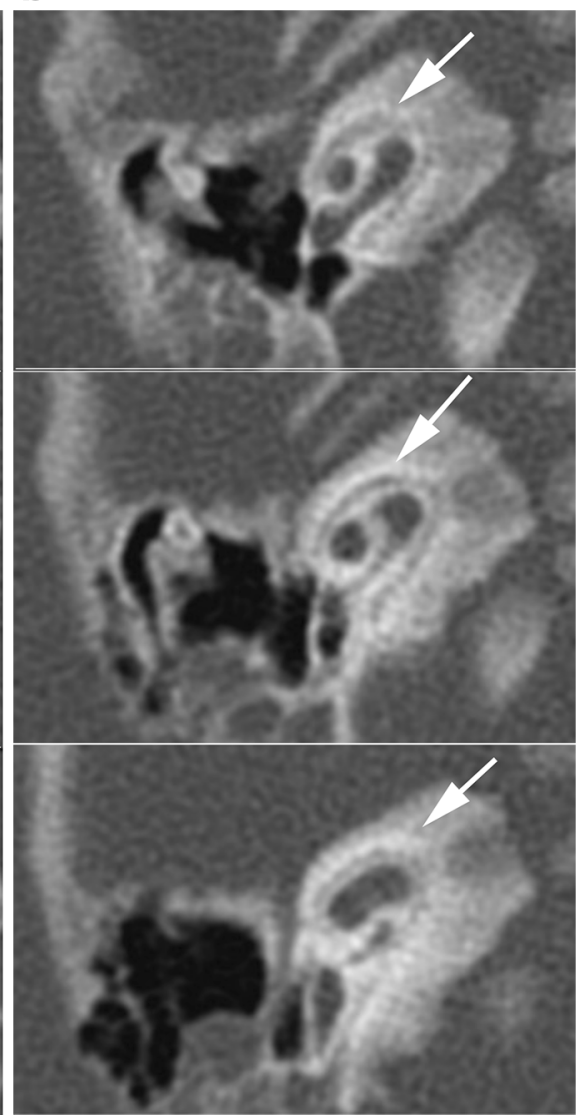

C

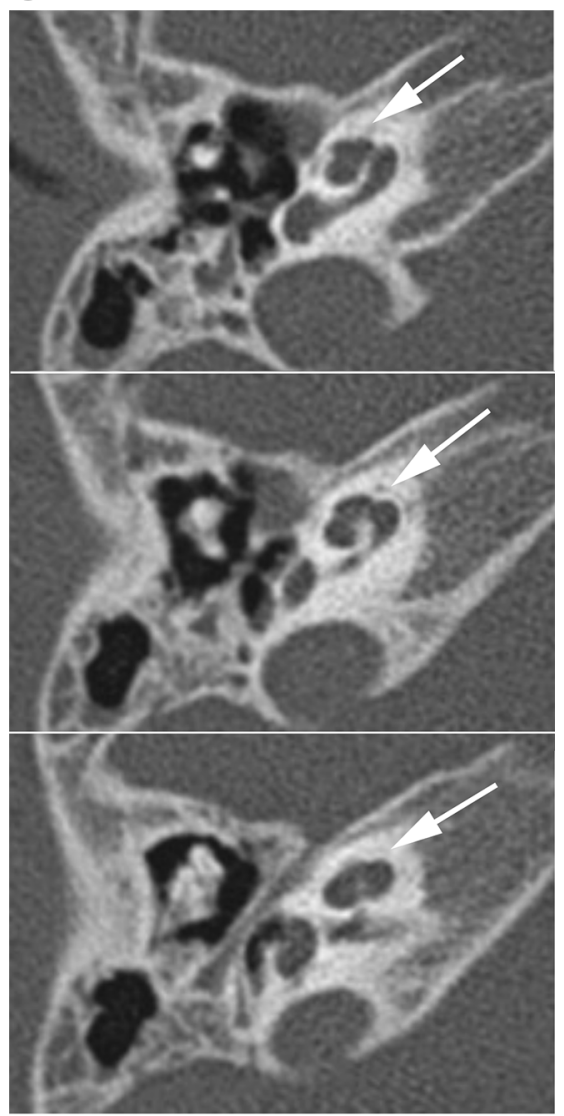

Fig. 4 Range of abnormalities of the cochlea seen in axial CT images. a Incomplete partitioning type II: normal development of the basal turn, but fusion of the second and apical turn seen in axial and coronal planes. b Hypoplasia type III: cochlea with less than 2 turns.
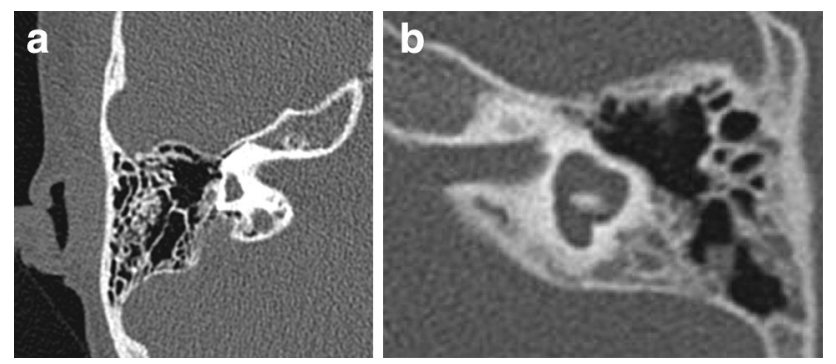

Fig. 5 Range of abnormalities of the vestibular system seen in axial CT images. a Aplasia of the semicircular canals in a right ear. b Dysplasia of the vestibule and semicircular canals in a left ear, with a malformed vestibule, shortened and dilated horizontal semicircular canal with small bony island, incomplete formation and dilatation of the posterior semicircular canal

frequently in patients with truncating mutations than in those with non-truncating mutations, but these results were not significant (Chi-squared test).

The patient without anomalies of the SCC, cochlea and windows, had a non-truncating mutation. In c Cochlea type 'IV': the basal, second and apical turns are present, but the second turn seems shortened, giving the cochlea an asymmetric, flattened appearance

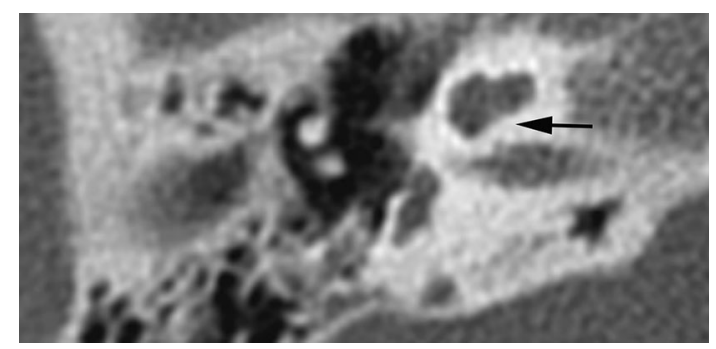

Fig. 6 Cochlear aperture-axial CT image shows a lacking cochlear aperture

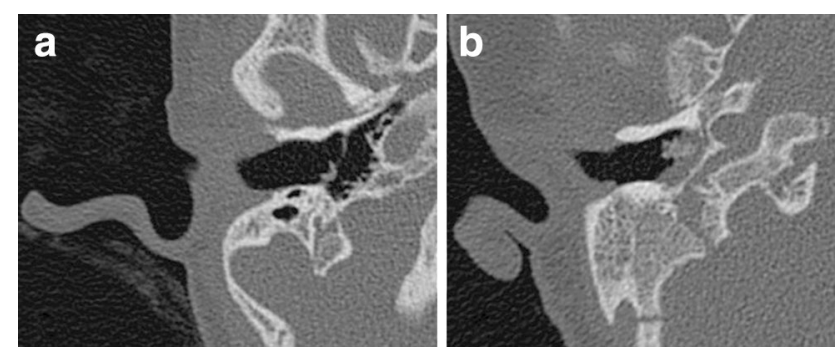

Fig. 7 Mastoid size-axial CT images of a small mastoid (a) and a wide mastoid (b); both ears had a grommet in situ 
Table 4 Mutations

\begin{tabular}{|c|c|c|c|}
\hline Patient no. & Mutation & Mutation type & Blake/Verloes criteria \\
\hline 1 & Nonsense & Truncating & Positive \\
\hline 2 & Missense & Non-truncating & Negative \\
\hline 3 & Nonsense & Truncating & Positive \\
\hline 4 & Nonsense & Truncating & Positive \\
\hline 5 & Splice-site & Non-truncating & Negative \\
\hline 6 & Splice-site & Non-truncating & Positive \\
\hline 7 & Nonsense & Truncating & Positive \\
\hline 8 & Missense & Non-truncating & Positive \\
\hline 9 & Splice-site & Non-truncating & Atypical \\
\hline 10 & Splice-site & non-truncating & Atypical \\
\hline 11 & Missense & Non-truncating & Atypical \\
\hline 12 & No mutation & & Atypical \\
\hline 13 & Missense & Non-truncating & Negative \\
\hline 14 & Frameshift & Truncating & Positive \\
\hline 15 & Frameshift & Truncating & Positive \\
\hline 16 & Nonsense & Truncating & Positive \\
\hline 17 & Nonsense & Truncating & Positive \\
\hline 18 & Missense & Non-truncating & Positive \\
\hline 19 & Nonsense & Truncating & Positive \\
\hline 20 & Frameshift & Truncating & Positive \\
\hline 21 & Splice-site & Non-truncating & Negative \\
\hline 22 & Nonsense & Truncating & Positive \\
\hline 23 & Splice-site & Non-truncating & Positive \\
\hline 24 & Nonsense & Truncating & positive \\
\hline 25 & Frameshift & Truncating & Positive \\
\hline 26 & Frameshift & Truncating & Positive \\
\hline 27 & Frameshift & Truncating & Positive \\
\hline 28 & Missense & Non-truncating & Positive \\
\hline 29 & Frameshift & Truncating & Positive \\
\hline 30 & UV missense & & Atypical \\
\hline 31 & Frameshift & Truncating & Partial \\
\hline 32 & Nonsense & Truncating & Positive \\
\hline 33 & Splice-site & Non-truncating & Positive \\
\hline 34 & Missense & Non-truncating & Positive \\
\hline 35 & Splice-site & Non-truncating & Atypical \\
\hline 36 & Nonsense & Truncating & Positive \\
\hline 37 & Nonsense & Truncating & Positive \\
\hline 38 & Frameshift & Truncating & Positive \\
\hline 39 & Nonsense & Truncating & Positive \\
\hline 40 & Frameshift & Truncating & Positive \\
\hline 41 & Nonsense & Truncating & Atypical \\
\hline 42 & Deletion & Truncating & Positive \\
\hline
\end{tabular}

$U V$ unknown variant

contrast, in the group with truncating mutations, there were no patients without anomalies of at least one of these structures.

\section{Discussion}

Analysis of the available imaging material and genetic information of the Dutch cohort of patients with CHARGE syndrome revealed a great variability in anomalies of the temporal bone with possible implications for cochlear implantation. More anomalies were found in patients with truncating $\mathrm{CHD} 7$ mutations than in those with non-truncating mutations. A shortcoming of this study is the variability in image quality leading to missing values of several fine anatomical structures (the imaging data were collected from different hospitals). Nevertheless, we were able to analyse the temporal bone and the anomalies, and to assess the potential impact on plans for cochlear implant surgery.

Temporal bone anomalies detected by $\mathrm{CT}$ are important when planning an operation. Vascular variations, missing anatomical landmarks such as the lateral semicircular canal or the vestibular system, an aberrant course of the facial nerve, or stenosis of the round window may hamper safe surgical access to the round window. Given our findings, when planning CI or ear surgery, care must be taken with regard to the reduced development of the mastoid, leading to a smaller access to the middle ear, especially in young children. In these cases, an endaural approach instead of a mastoidectomy [7], or a temporary intra-operative removal or anterior displacement of the posterior wall of the outer ear canal could be considered. Vascular anomalies could also complicate a mastoidectomy, since these may cause uncontrollable bleeding during surgery or postoperative thrombosis of the sigmoid sinus [8-10]. In our group of CHARGE patients, large emissary veins and a persistent petrosquamosal sinus were often present. Whereas emissary veins through the temporal squama are a common anatomical variant $[11,12]$ and easily dealt with during surgery, a persistent petrosquamosal sinus is rare in the general population (Koesling et al. [11] estimated this at $1 \%)$. However, several authors have reported it to be present in 11-89\% of CHARGE patients [9, 13-15]. The highest incidence was described by Giesemann et al. [14], in patients who all had aplasia of the SCCs. In our patient population, which included patients with partially and fully developed vestibular systems, a persistent petrosquamosal sinus was seen in $13 \%$. The persistent petrosquamosal sinus can impede the surgical approach, this can be a reason to choose the contra lateral ear for CI.

SCC aplasia is a hallmark of CHARGE syndrome. CHD7 is highly expressed in the developing ear and is required for development of the SCCs. Delayed fusion and altered gene expression contribute to SCC defects in CHD7-deficient mice [16]. Currently, the presence of SCC abnormalities is considered an important indication for performing sequencing of the $C H D 7$ gene and diagnosis 
Table 5 Distribution of cochlear types for different types of mutations

\begin{tabular}{lllll}
\hline Cochlear type & Normal & IPII $^{\mathrm{a}}$ & Hypoplasia type III & Hypoplasia type IV \\
\hline Total & $49(61.2 \%)$ & $7(8.3 \%)$ & $3(3.8 \%)$ & $21(26.3 \%)$ \\
Truncating mutations & $27(33.8 \%)$ & $6(7.5 \%)$ & $3(3.8 \%)$ & $14(17.5 \%)$ \\
Non-truncating mutations & $22(27.5 \%)$ & $1(1.3 \%)$ & 0 & $7(8.8 \%)$ \\
\hline
\end{tabular}

Number of ears: 80 (patients 12 and 30 excluded)

${ }^{a}$ Incomplete partition type II without enlarged vestibular aqueduct or dilated vestibulum; $P=0.194\left(\chi^{2}\right)$

Table 6 Distribution of semicircular canal malformations for different types of mutations

\begin{tabular}{|c|c|c|c|c|c|c|c|}
\hline Defect & $\begin{array}{l}\text { SCC } \\
\text { normal }\end{array}$ & $\begin{array}{l}\text { PSCC } \\
\text { dysplasia }\end{array}$ & $\begin{array}{l}\text { SSCC } \\
\text { dysplasia }\end{array}$ & $\begin{array}{l}\text { PSCC + LSCC } \\
\text { dysplasia }\end{array}$ & $\begin{array}{l}\text { SCCC + LSCCC } \\
\text { dysplasia }\end{array}$ & All aplastic & $\begin{array}{l}\text { All } \\
\text { dysplastic }\end{array}$ \\
\hline Total & $2(2.5 \%)$ & $4(5.0 \%)$ & $5(6.3 \%)$ & $1(1.3 \%)$ & $2(2.5 \%)$ & $63(78.8 \%)$ & $3(3.8 \%)$ \\
\hline Truncating & 0 & 0 & $3(3.8 \%)$ & 0 & 0 & $46(57.5 \%)$ & $1(1.3 \%)$ \\
\hline $\begin{array}{l}\text { Non- } \\
\text { truncating }\end{array}$ & $2(2.5 \%)$ & $4(5.0 \%)$ & $2(2.5 \%)$ & $1(1.3 \%)$ & $2(2.5 \%)$ & $17(21.3 \%)$ & $2(2.5 \%)$ \\
\hline
\end{tabular}

Number of ears: 80 (patients 12 and 30 excluded); $P=0.004\left(\chi^{2}\right)$

SCC semicircular canals, PSCC posterior semicircular canal, SSCC superior semicircular canal, LSCC lateral semicircular canal

Table 7 Surgical challenges in cochlear implantation

\begin{tabular}{llll}
\hline Surgical step & Structure on CT & Anomaly & Surgical challenge \\
\hline Mastoidectomy & Mastoid & Underdeveloped & Reduced access to the middle ear \\
& Vascular structures & Large emissary vein & Unexpected bleeding \\
& Semicircular canals & PSS & Bleeding, reduced mastoid size \\
Post. tympanotomy & Facial nerve & More medial route & Loss of landmark \\
Cochleostomy & Ossicles & Dysplasia & Facilitates entrance to the middle ear \\
& Facial nerve & Aberrant route & Obstructed vision by the incus \\
& Windows & Round window stenosis & Impedes cochleostomy \\
Insertion & Jugular bulb & High & Choosing optimal side for cochleostomy \\
\hline
\end{tabular}

Post. posterior, PSS petrosquamosal sinus

Table 8 Combinations of anomalies often seen

\begin{tabular}{lll}
\hline Anomaly & $\begin{array}{l}\text { In combination } \\
\text { with }\end{array}$ & $\begin{array}{l}\text { Number of patients } \\
\text { (percentage of } \\
\text { all patients) }\end{array}$ \\
\hline Absent RW & Absent OW & $12(14.3 \%)$ \\
Stenotic OW & $\begin{array}{l}\text { Dysplastic } \\
\text { stapes }\end{array}$ & $23(27.3 \%)$ \\
Aberrant tympanic & $\begin{array}{c}\text { Dysplastic } \\
\text { portion facial nerve }\end{array}$ & $24(28.6 \%)$ \\
Total SCC hypoplasia & $\begin{array}{c}\text { OW stenosis } \\
\text { Aberrant VA }\end{array}$ & $21(25.0 \%)$ \\
& $\begin{array}{c}\text { SCC } \\
\text { hypoplasia }\end{array}$ & $14(16.7 \%)$ \\
& with SCA & \\
& SCC hypoplasia & $14(16.7 \%)$ \\
& without SCA &
\end{tabular}

$\overline{O W}$ oval window, $R W$ round window, $S C C$ semicircular canals, $S C A$ stenotic cochlear aperture, $V A$ vestibular aqueduct
[17]. In our study, we found that normal SCC were present in only one patient. However, during mastoidectomy, the lateral SCC serves as an important anatomical landmark, so the appearance of the SCCs, ranging from complete absence of all canals to normal development, should be meticulously described [7, 13]. In case of a lateral SCC aplasia, the tegmen serves as a paramount marker to direct the surgeon towards the antrum. Anomalies of the SCCs were associated with hypoplasia of the vestibule and a shortened vestibular aqueduct coursing straight to the posterior fossa. This confirms what was reported by Morimoto et al.: 'An aberrant course of the vestibular aqueduct is hypothesized to be the result of semicircular aplasia and the associated displacement of normal surrounding structures' [9].

The facial nerve is another structure at risk during cochlear implantation. As described in the literature, the 
facial nerve often showed an aberrant course in its tympanic or mastoidal portion $[9,13,18]$. The more medial course of the mastoidal portion of the facial nerve allows a surgeon to create a wider entrance to the middle ear (through a posterior tympanotomy). However, the aberrant course of the tympanic segment of the facial nerve, in particular when it covers the round window, may complicate creating the cochleostomy for intracochlear insertion of the cochlear implant. The aberrant facial nerve may be at risk of injury during cochleostomy [19] or may even be a reason to abort the implantation [20]. The association we observed of an aberrant course of the facial nerve with dysplastic stapes and absence of the oval window was described by Zeifer et al. in different aetiologies without CHARGE syndrome [21].

Absence or stenosis of the oval window was present in more than two-thirds of our patients and is a well-known feature in CHARGE syndrome [9, 13, 22, 23]. Stenosis or absence of the round window was seen less often (as confirmed in the literature). Yet this poses an additional challenge for the surgeon in choosing the optimal site for a cochleostomy.

The size and shape of the cochlea will influence the choice of CI-type. According to the literature, the cochlea is dysplastic in between 20 and $100 \%$ of the ears described in patients with CHARGE syndrome [9, 18, 24, 25]. The anomalies vary from a fused second and apical turn to a cochlea with 1.5 turns [26-28]. We describe several cases with a shortened cochlea despite the presence of a basal, second and apical turn (referred to as hypoplasia type IV). To the best of our knowledge, this cochlear appearance has not been described in CHARGE syndrome before, but it appears to be consistent with the description of cochlear hypoplasia type IV in a recently published study by Sennaroglu [29] or may be comparable with the flattened cochlea observed by Elmaleh et al. [30] in patients with Waardenburg syndrome. However, the other temporal bone anomalies described in Waardenburg syndrome, besides SCC aplasia and the flattened cochlea, differ from our findings.

Both this cochlear anomaly, as well as the IPII and hypoplasia type III found in this study, should not cause any problems for the insertion of an electrode array as opposed to more severe malformations [31, 32]. The successful outcome of a cochlear implantation also depends on the presence of the cochleo-vestibular nerve.

In our phenotype-genotype analysis we showed that total aplasia of the SCC and oval window aplasia is more common in patients with truncating mutations than in those with non-truncating mutations-in agreement with the results of Corsten-Janssen et al. showing more anomalies in patients with truncating mutations [33]. Remarkably, the distribution of mutations present in our cohort differs from that reported for large cohorts in the literature. Our percentage of patients with non-truncating mutations (splicesite and missense) was relatively high with $35.7 \%$ in comparison to Zentner et al. [5] and to Janssen et al. [4] who reported 23 and $20 \%$ of patients with non-truncating mutations, respectively. This discrepancy might be because a CT is often used in mildly affected patients to check the semicircular canals and to provide further proof for the clinical diagnosis. Our cohort might be enriched with more mildly affected patients (12/42), and thus of missense mutations.

In general, we conclude that temporal bone findings in patients with CHARGE syndrome vary widely and should therefore be studied meticulously before performing any surgery. Imaging may exclude patients from cochlear implantation or reveal an aberrant course of the facial nerve, vascular and middle ear abnormalities that could complicate CI surgery. Such information is valuable and should be combined with records on the developmental and behavioural problems that are also common in CHARGE syndrome. Moreover, patients with CHARGE syndrome often have post-surgical complications due to their neurological and anatomical abnormalities [34]. A balance between the benefit of CI, the surgical procedure's chance of success, and the anaesthetic risks should be sought by a multi-disciplinary team working with the patient and his/ her family.

Acknowledgments We thank parents of patients for giving the permission to use their data. We thank Jackie Senior for editing the manuscript. This study was funded by Cochlear BV.

\section{Compliance with ethical standards}

Conflict of interest All authors declare that they have no conflict of interest.

Ethical approval All procedures performed in the studies involving human participants were in accordance with the ethical standards of the institutional and/or national research committee and with the 1964 Helsinki declaration and its later amendments or comparable ethical standards.

Informed consent Informed consent was obtained from all individual participants included in the study.

Open Access This article is distributed under the terms of the Creative Commons Attribution 4.0 International License (http://crea tivecommons.org/licenses/by/4.0/), which permits unrestricted use, distribution, and reproduction in any medium, provided you give appropriate credit to the original author(s) and the source, provide a link to the Creative Commons license, and indicate if changes were made.

\section{Appendix}

See Tables 9 and 10. 
Table 9 Radiologic criteria for the os petrosum in patients with CHARGE syndrome

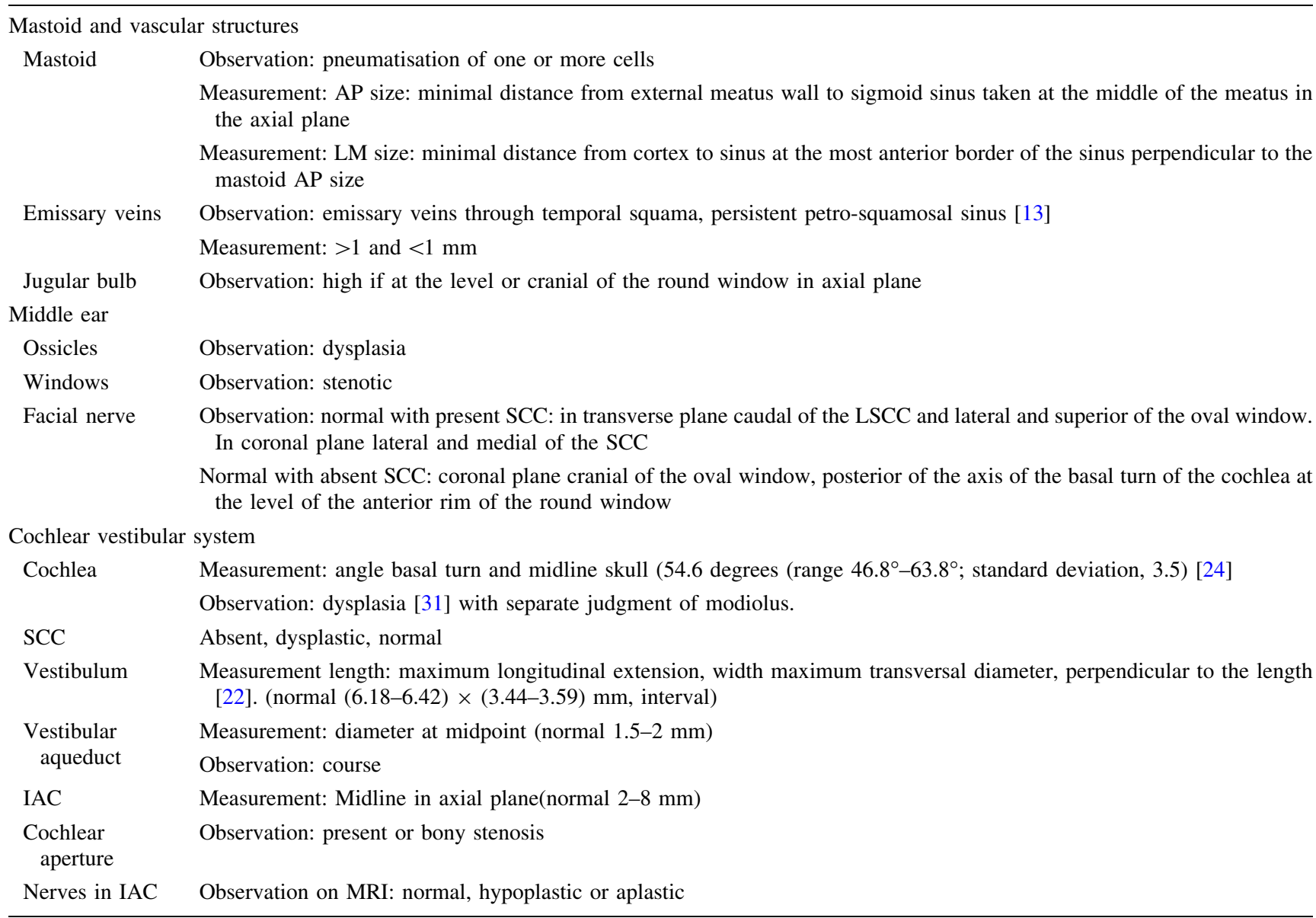

$A P$ anterior-posterior, $L M$ lateral-medial, SCC semicircular canal, $L S C C$ lateral semicircular canal, IAC internal auditory canal 
Table 10 Radiologic set of criteria for CT scan

\begin{tabular}{|l|l|}
\hline Name Observer & \\
\hline Date & \\
\hline ID scan & $\square$ good \\
\hline Quality Image & $\square$ moderate \\
& $\square$ bad \\
\hline
\end{tabular}

\begin{tabular}{|c|c|c|}
\hline Item & AD & AS \\
\hline $\begin{array}{l}\text { Cochlea - } \\
\text { External contours: } \\
2.5 \text { turn? }\end{array}$ & $\begin{array}{l}\square \text { yes } \\
\square \text { no } \\
\square \text { unable to identify }\end{array}$ & $\begin{array}{l}\square \text { yes } \\
\square \text { no } \\
\square \text { unable to identify }\end{array}$ \\
\hline $\begin{array}{l}\text { Cochlea internal: } \\
\text { Interscalar septa present? }\end{array}$ & $\begin{array}{l}\square \text { yes } \\
\square \text { no } \\
\square \text { unable to identify }\end{array}$ & $\begin{array}{l}\square \text { yes } \\
\square \text { no } \\
\square \text { unable to identify }\end{array}$ \\
\hline Modiolus & $\begin{array}{l}\square \text { present } \\
\square \text { absent } \\
\square \text { unable to identify }\end{array}$ & $\begin{array}{l}\square \text { present } \\
\square \text { absent } \\
\square \text { unable to identify }\end{array}$ \\
\hline Angle of basal turn & & \\
\hline $\begin{array}{l}\text { Cochlear aperture: } \\
\text { Is an aperture visible? }\end{array}$ & $\begin{array}{l}\square \text { yes } \\
\square \text { no }\end{array}$ & $\begin{array}{l}\square \text { yes } \\
\square \text { no }\end{array}$ \\
\hline
\end{tabular}


Table 10 continued

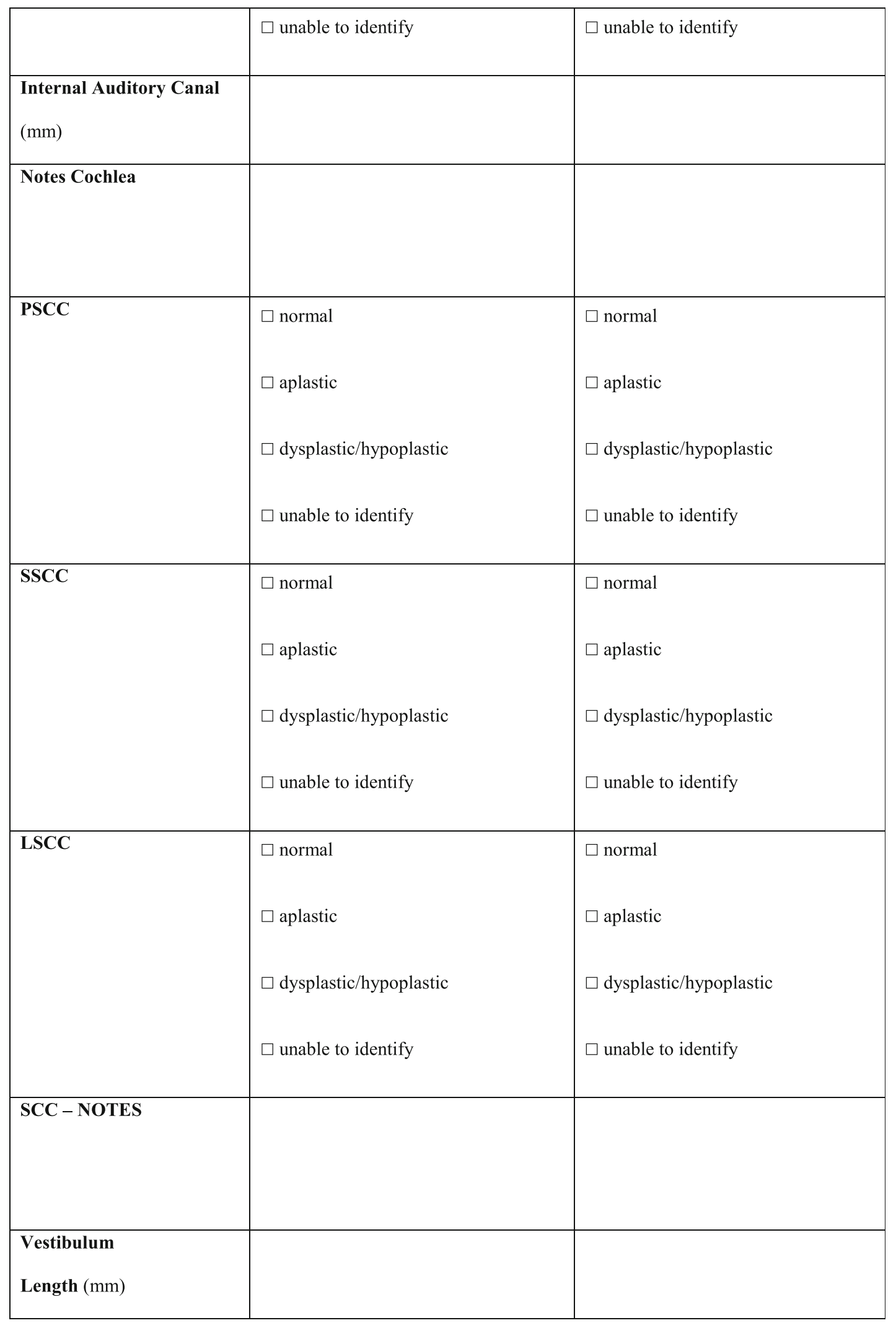


Table 10 continued

\begin{tabular}{|c|c|c|}
\hline Vestibulum width $(\mathrm{mm})$ & & \\
\hline $\begin{array}{l}\text { Vestibular Aqueduct } \\
\text { Diameter (mm) }\end{array}$ & & \\
\hline $\begin{array}{l}\text { Vestibular Aqueduct } \\
\text { Course }\end{array}$ & $\begin{array}{l}\square \text { normal } \\
\square \text { aberrant } \\
\square \text { unable to identify }\end{array}$ & $\begin{array}{l}\square \text { normal } \\
\square \text { aberrant } \\
\square \text { unable to identify }\end{array}$ \\
\hline $\begin{array}{l}\text { Vestibular aqueduct - } \\
\text { NOTES }\end{array}$ & & \\
\hline Oval window & $\begin{array}{l}\square \text { present } \\
\square \text { absent/stenotic } \\
\square \text { unable to identify }\end{array}$ & $\begin{array}{l}\square \text { present } \\
\square \text { absent/stenotic } \\
\square \text { unable to identify }\end{array}$ \\
\hline Round window & $\begin{array}{l}\square \text { present } \\
\square \text { absent/stenotic } \\
\square \text { unable to identify }\end{array}$ & $\begin{array}{l}\square \text { present } \\
\square \text { absent/stenotic } \\
\square \text { unable to identify }\end{array}$ \\
\hline Windows - NOTES & & \\
\hline Stapes & $\begin{array}{l}\square \text { normal } \\
\square \text { dysplastic } \\
\square \text { unable to identify }\end{array}$ & $\begin{array}{l}\square \text { normal } \\
\square \text { dysplastic } \\
\square \text { unable to identify }\end{array}$ \\
\hline Incus & $\square$ normal & $\square$ normal \\
\hline
\end{tabular}


Table 10 continued

\begin{tabular}{|c|c|c|}
\hline & $\begin{array}{l}\square \text { dysplastic } \\
\square \text { unable to identify }\end{array}$ & $\begin{array}{l}\square \text { dysplastic } \\
\square \text { unable to identify }\end{array}$ \\
\hline Malleus & $\begin{array}{l}\square \text { normal } \\
\square \text { dysplastic } \\
\square \text { unable to identify }\end{array}$ & $\begin{array}{l}\square \text { normal } \\
\square \text { dysplastic } \\
\square \text { unable to identify }\end{array}$ \\
\hline Ossicles - NOTES & & \\
\hline $\begin{array}{l}\text { Facial nerve tympanic } \\
\text { segment }\end{array}$ & $\begin{array}{l}\square \text { Normal } \\
\square \text { aberrant } \\
\square \text { unable to identify }\end{array}$ & $\begin{array}{l}\square \text { Normal } \\
\square \text { aberrant } \\
\square \text { unable to identify }\end{array}$ \\
\hline $\begin{array}{l}\text { Facial nerve tympanic } \\
\text { segment - NOTES }\end{array}$ & & \\
\hline $\begin{array}{l}\text { Facial nerve mastoid } \\
\text { segment }\end{array}$ & $\begin{array}{l}\square \text { Normal } \\
\square \text { aberrant } \\
\square \text { unable to identify }\end{array}$ & $\begin{array}{l}\square \text { Normal } \\
\square \text { aberrant } \\
\square \text { unable to identify }\end{array}$ \\
\hline $\begin{array}{l}\text { Facial nerve mastoid } \\
\text { segment - NOTES }\end{array}$ & & \\
\hline Mastoid AP-size (mm) & & \\
\hline Mastoid LM-size (mm) & & \\
\hline Mastoid pneumatisation? & $\square$ yes & $\square$ yes \\
\hline
\end{tabular}


Table 10 continued

\begin{tabular}{|c|c|c|}
\hline & $\begin{array}{l}\square \text { no } \\
\square \text { unable to identify }\end{array}$ & $\begin{array}{l}\square \text { no } \\
\square \text { unable to identify }\end{array}$ \\
\hline Jugular Bulb & $\begin{array}{l}\square \text { normal } \\
\square \text { high } \\
\square \text { unable to identify }\end{array}$ & $\begin{array}{l}\square \text { normal } \\
\square \text { high } \\
\square \text { unable to identify }\end{array}$ \\
\hline Emissary veins & $\begin{array}{l}\square \text { absent } \\
\square<1 \mathrm{~mm} \\
\square>1 \mathrm{~mm} \\
\square \text { unable to identify }\end{array}$ & $\begin{array}{l}\square \text { absent } \\
\square<1 \mathrm{~mm} \\
\square>1 \mathrm{~mm} \\
\square \text { unable to identify }\end{array}$ \\
\hline Petrosquameuse sinus & $\begin{array}{l}\square \text { absent } \\
\square \text { present } \\
\square \text { unable to identify }\end{array}$ & $\begin{array}{l}\square \text { absent } \\
\square \text { present } \\
\square \text { unable to identify }\end{array}$ \\
\hline $\begin{array}{l}\text { Vascular structures } \\
\text { NOTES }\end{array}$ & & \\
\hline NOTES overall & & \\
\hline
\end{tabular}

PSCC posterior semicircular canal, SSCC superior semicircular canal, LSCC lateral semicircular canal, SCC semicircular canal, AP anteriorposterior, $L M$ lateral-medial 


\section{References}

1. Blake KD, Davenport SL, Hall BD et al (1998) CHARGE association: an update and review for the primary pediatrician. Clin Pediatr (Phila) 37:159-173

2. Verloes A (2005) Updated diagnostic criteria for CHARGE syndrome: a proposal. Am J Med Genet A 133A:306-308

3. Jongmans MC, Admiraal RJ, van der Donk KP et al (2006) CHARGE syndrome: the phenotypic spectrum of mutations in the CHD7 gene. J Med Genet 43:306-314

4. Janssen N, Bergman JE, Swertz MA et al (2012) Mutation update on the CHD7 gene involved in CHARGE syndrome. Hum Mutat 33:1149-1160

5. Zentner GE, Layman WS, Martin DM, Scacheri PC (2010) Molecular and phenotypic aspects of CHD7 mutation in CHARGE syndrome. Am J Med Genet A 152A:674-686

6. Bergman JE, de Wijs I, Jongmans MC, Admiraal RJ, Hoefsloot LH, van Ravenswaaij-Arts CM (2008) Exon copy number alterations of the CHD7 gene are not a major cause of CHARGE and CHARGE-like syndrome. Eur J Med Genet 51:417-425

7. Stjernholm C (2003) Aspects of temporal bone anatomy and pathology in conjunction with cochlear implant surgery. Acta Radiol Suppl 430:2-15

8. Marsot-Dupuch K, Gayet-Delacroix M, Elmaleh-Berges M, Bonneville F, Lasjaunias P (2001) The petrosquamosal sinus: CT and MR findings of a rare emissary vein. AJNR Am J Neuroradiol 22:1186-1193

9. Morimoto AK, Wiggins RH 3rd, Hudgins PA et al (2006) Absent semicircular canals in CHARGE syndrome: radiologic spectrum of findings. AJNR Am J Neuroradiol 27:1663-1671

10. An YH, Wee JH, Han KH, Kim YH (2011) Two cases of petrosquamosal sinus in the temporal bone presented as perioperative finding. Laryngoscope 121:381-384

11. Koesling S, Kunkel P, Schul T (2005) Vascular anomalies, sutures and small canals of the temporal bone on axial CT. Eur J Radiol 54:335-343

12. Louis RG Jr, Loukas M, Wartmann CT et al (2009) Clinical anatomy of the mastoid and occipital emissary veins in a large series. Surg Radiol Anat 31:139-144

13. Satar B, Mukherji SK, Telian SA (2003) Congenital aplasia of the semicircular canals. Otol Neurotol 24:437-446

14. Giesemann AM, Goetz GF, Neuburger J, Lenarz T, Lanfermann H (2011) Persistent petrosquamosal sinus: high incidence in cases of complete aplasia of the semicircular canals. Radiology 259:825-833

15. Friedmann DR, Amoils M, Germiller JA et al (2012) Venous malformations of the temporal bone are a common feature in CHARGE syndrome. Laryngoscope 122:895-900

16. Hurd EA, Micucci JA, Reamer EN, Martin DM (2012) Delayed fusion and altered gene expression contribute to semicircular canal defects in Chd7 deficient mice. Mech Dev 129:308-323

17. Bergman JE, Janssen N, Hoefsloot LH, Jongmans MC, Hofstra RM, van Ravenswaaij-Arts CM (2011) CHD7 mutations and CHARGE syndrome: the clinical implications of an expanding phenotype. J Med Genet 48:334-342
18. Lanson BG, Green JE, Roland JT Jr, Lalwani AK, Waltzman SB (2007) Cochlear implantation in Children with CHARGE syndrome: therapeutic decisions and outcomes. Laryngoscope 117:1260-1266

19. Ahn JH, Lee KS (2013) Outcomes of cochlear implantation in children with CHARGE syndrome. Acta Otolaryngol 133:1148-1153

20. Bauer PW, Wippold FJ 2nd, Goldin J, Lusk RP (2002) Cochlear implantation in children with CHARGE association. Arch Otolaryngol Head Neck Surg 128:1013-1017

21. Zeifer B, Sabini P, Sonne J (2000) Congenital absence of the oval window: radiologic diagnosis and associated anomalies. AJNR Am J Neuroradiol 21:322-327

22. Admiraal RJ, Joosten FB, Huygen PL (1998) Temporal bone CT findings in the CHARGE association. Int $\mathrm{J}$ Pediatr Otorhinolaryngol 45:151-162

23. Arndt S, Beck R, Schild C, Grauvogel TD, Laszig R, Aschendorff A (2010) Management of cochlear implantation in patients with malformations. Clin Otolaryngol 35:220-227

24. Holcomb MA, Rumboldt Z, White DR (2013) Cochlear nerve deficiency in children with CHARGE syndrome. Laryngoscope 123:793-796

25. Song MH, Cho HJ, Lee HK et al (2011) CHD7 mutational analysis and clinical considerations for auditory rehabilitation in deaf patients with CHARGE syndrome. PLoS One 6:e24511

26. Guyot JP, Gacek RR, DiRaddo P (1987) The temporal bone anomaly in CHARGE association. Arch Otolaryngol Head Neck Surg 113:321-324

27. Glueckert R, Rask-Andersen H, Sergi C et al (2010) Histology and synchrotron radiation-based microtomography of the inner ear in a molecularly confirmed case of CHARGE syndrome. Am J Med Genet A 152A:665-673

28. Haginomori S, Sando I, Miura M, Casselbrant ML (2002) Temporal bone histopathology in CHARGE association. Ann Otol Rhinol Laryngol 111:397-401

29. Sennaroglu L, Yucel E, Sennaroglu G, Ozgen B (2015) Management of Children with Inner Ear Malformations. In: Publishers JM, (ed.) Sataloff's comprehensive textbook of otolaryngology: head and neck surgery (pediatric otolaryngology), p 91-106

30. Elmaleh-Berges M, Baumann C, Noel-Petroff N et al (2013) Spectrum of temporal bone abnormalities in patients with Waardenburg syndrome and SOX10 mutations. AJNR Am J Neuroradiol 34:1257-1263

31. Mylanus EA, Rotteveel LJ, Leeuw RL (2004) Congenital malformation of the inner ear and pediatric cochlear implantation. Otol Neurotol 25:308-317

32. Sennaroglu L (2010) Cochlear implantation in inner ear malformations-a review article. Cochlear Implants Int 11:4-41

33. Bergman JE, Janssen N, van der Sloot AM et al (2012) A novel classification system to predict the pathogenic effects of CHD7 missense variants in CHARGE syndrome. Hum Mutat 33:1251-1260

34. Blake K, MacCuspie J, Hartshorne TS, Roy M, Davenport SL, Corsten G (2009) Postoperative airway events of individuals with CHARGE syndrome. Int J Pediatr Otorhinolaryngol 73:219-226 